From the symbolic hermeneutics developed by the Circle of Eranos, and concepts like myth and symbol, this article aim to reflect about the artist's myth as an extension of Hero's myth. To identify the heroic myth as a point of reference in the artistic identity construction, I introduce mythcritic as methodology.

Key-Words: symbol, myth, artist's figure 


\section{O mito do artista como extensão do mito do herói}

Francielly Rocha

DOSSIN

A partir da hermenêutica simbólica desenvolvida pelo Círculo de Eranos e de conceitos como mito e símbolo, este artigo visa refletir sobre o mito do artista como extensão do mito do herói. Para podermos identificar o mito heróico como ponto de referência na construção da identidade artística, apresenta a mitocrítica como metodologia.

Palavras-chaves: símbolo, mito, figura do artista 


\section{Mito e símbolo}

Toda fala da experiência artística é mito, todo mito é poesia

Intelectualizar a arte é sempre uma tarefa árdua e intangível em sua completude. Podemos, ao invés de imbuir-nos de uma missão que de antemão se mostra frustrada, ser conscientes de que tangemos apenas partes do objeto em questão, o alcançamos apenas por uma aproximação, tão plena de interstícios e fendas quanto à própria arte. Se toda fala da experiência artística é poesia, devemos retê-la também na construção de um texto que se propõe a pensar a arte.

Especula-se que a arte tenha surgido a partir de práticas rituais e mágicas. Pinturas e esculturas de períodos da chamada "pré-história" sobreviveram ao tempo, possibilitando especulações científicas, como dos arqueólogos. Naturalmente, expressões artísticas como a dança e o teatro não proporcionam tais formas de registro, fazendo com que a verdade em torno da origem da arte permaneça na ordem do inefável.

No entanto, a hipótese da ligação entre a arte e práticas mágicas é bastante crível, principalmente quando nos atemos ao desenvolvimento da arte na história, em sua forma linear como estamos habituados. A partir do momento em que o homem teve consciência de sua "situação" no mundo, a questão que o atormenta desde então é sobre sua brevidade e possível posteridade. A morte é a grande impulsionadora, pois se constitui no fato mais transtornador da vida. Para poder suportá-la o homem cria, acontecimento esse onde pode projetar a transcendência. $\mathrm{Na}$ arte vemos e vivenciamos metáforas da existência e alegorias da morte.

Toda prática humana se constitui como forma de buscar sentido para sua existência, mas a arte, como uma forma de linguagem, é então o lugar de excelência para a expressão dessa falta na busca de preenchê-la. Segundo o filósofo Théodore Jouffroy, "somente o invisível nos comove" (apud MANGUEL, 2003, p. 222), é este vácuo presente numa obra de arte que nos "atinge", da mesma maneira que é justamente esse vazio que conduz a obra de arte e nossa relação com ela a um caráter de transcendência, e também, 
porque não dizer, mágica. Afinal, nossa relação com a arte não se dá apenas através recognição da qualidade estética ou sua relevância histórico-social. É o que nos explica Vargas (2005, p. 19), "[...] O reconhecimento da qualidade da obra de arte não se limita a reconhecer o conhecimento da linguagem ou da história da linguagem, mas também é o reconhecimento de uma revelação, de um mistério".

A ciência no período da construção de seu discurso fundador precisou negar o que a precedeu para poder, enfim, conquistar seu posto que hoje ocupa de forma privilegiada e quase hegemônica em nossa sociedade. Como resultado disso, o discurso científico criou certos preconceitos vinculados a termos como magia, transcendência, mitologia e mito. Esses foram, e são vistos como superstições, histórias falsas, "coisas do homem primitivo e ignorante", e são situados em oposição ao racional e à ciência. Desconsiderando, assim, as duas formas de pensamento como relacionais e igualmente inerentes ao homem. Apesar de negar a validade daqueles, podemos notar a presença do mito em toda nossa fala e comportamento. Dessa forma, o mito e a mitologia são boas fontes/formas para pensarmos modelos de comportamento e seus significados, principalmente em relação à permanência de modelos artísticos, é o que se propõe a mitocrítica.

Mesmo não se oferecendo a ser de fato uma metodologia para análise e leitura de obras artísticas e críticas, a hermenêutica simbólica se constitui como base para uma reflexão epistemológica sobre os elementos que nos conduzem a relação dessas.

A hermenêutica simbólica do Círculo de Eranos $^{2}$ (Eranoskreis) nasceu na Europa no período entre guerras, mais especificamente na década de 30, na forma de um grupo interdisciplinar, com o objetivo de trazer diferentes concepções filosóficas e confrontálas com a concepção predominante no ocidente. Sabe-se que esse período histórico foi marcado pela desilusão acerca do pensamento econômico, científico e tecnológico, que sob a égide "civilizacional", não pode conter crises como a de 1929, nos EUA, e a implosão da Primeira Grande Guerra Mundial que culminou ainda na Segunda Grande Guerra Mundial ${ }^{3}$, as quais o historiador Eric Hobsbawn, por exemplo, chama de "Guerras Totais". Segundo ele, "para os que cresceram antes de 1914, o contraste foi tão impressionante 
que muitos [...] se recusaram a ver qualquer continuidade com o passado" (HOBSBAWN, 1995, p. 30). Essas experiências impulsionaram o esforço para encontrar formas alternativas para o pensamento ocidental que se mostrava então tão desastroso.

A inspiração teórica do Círculo de Eranos foi Carl G. Jung, o que justifica a direção junguiana que o grupo toma desde o início. Muitos reconhecidos pensadores fizeram parte do grupo, dentre eles, o mitólogo Joseph Campbell que se dedicou principalmente ao estudo do mito do herói, o romeno Mircea Eliade já bastante conhecido dos acadêmicos brasileiros, e o antropólogo Gilbert Durand que desenvolve a mitocrítica, metodologia para análise de obras literárias, infelizmente ainda pouco conhecido e estudado no Brasil.

O conteúdo conceitual erosiano centra-se no estudo da mitologia e do mito que é o veículo no símbolo. O conceito de símbolo é o que difere o pensamento do Círculo de Eranos de outras correntes do pensamento como, por exemplo, o estruturalismo. Difere também da hermenêutica filosófica, na qual Gadamer é um dos maiores representantes. Nesta o homem é marcado pela tradição e cultura. Para Gadamer (1985), estamos imersos na história e não há possibilidade de nos situarmos fora dela. Já sob o ponto de vista da hermenêutica simbólica o mito antecede a história, logo, qualquer consciência histórica é, em verdade, precedida de uma inconsciência mítica.

Sobre a questão o pesquisador, professor e artista Antônio Vargas (2006, p. 26) diz, "Durand esclarece que sem o funcionamento das estruturas míticas não há inteligência histórica possível, já que é a existência de uma mitologia 'mãe' que permite que os acontecimentos históricos sejam 'inscritos' em uma narrativa com sentido coletivo". Não obstante, esse entendimento se dá também pela negação do conceito de história como linearidade e evolução.

O símbolo, principal conceito, assim como os outros conceitoschave da tradição erosiana, é bastante complexo, ambíguo e inesgotável. Defini-lo é uma tarefa escorregadia, até porque estamos na ordem do simbólico o que dificulta sua identificação, mas mesmo assim é sempre uma manifestação concreta. O símbolo aqui apresentado não corresponde ao símbolo/signo 
semiótico, pois ele é uno, sendo ao mesmo tempo significante e significado, não tem objetividade em si, também não contém apenas subjetividade. Ele é conduzido através do mito (narrativa), e seu sentido se constrói através das redundâncias sincrônicas.

O símbolo é também relação, não permitindo distanciamento e exigindo afetividade, por isso algo é símbolo para uma pessoa quando esse algo existe nela e para ela, lembrando que o substancial nesta instância é menos os pólos desta relação do que a própria relação. Portanto, o símbolo foge à ordem da razão e se instaura na ordem do transcendental. As grandes imagens inseridas na história da arte, por exemplo, nos pertencem como símbolos. Assim, a atividade artística e até mesmo a própria idéia de arte podem também ser entendidas como símbolos.

Em toda relação há um pr-conceito, ou concepção que a antecede. Essa concepção para Gadamer é histórica, enquanto a hermenêutica simbólica não se detém na história e na realidade como expressão dialética, pois há sempre o elemento de poesia, de elevação que não se deixa reduzir.

Para a hermenêutica simbólica, antes da história há o mito, que seria então pr-conceito. O que explica o símbolo é esse conceito prévio não racionalizável. Quando o símbolo necessita de explicação ele deixa de ser, se instaura uma crise e perde seu sentido gerando outra significação, talvez menos rica. Ele é o que desencadeia na pessoa, uma espécie de epifania. O símbolo está presente no mito, que por sua vez, tenta dar conta da singularidade simbólica, ligando o homem ao mundo.

\section{O mito do herói e o mito do artista}

Vários mitos atuam numa sociedade, uns emergem e outros submergem. Um mito, como o do herói, pode ser visto por um olhar histórico e social no sentido de que dentre suas diversas características, algumas são mais ou menos enfatizadas dependendo de seu contexto.

Um dos maiores símbolos é o mito do herói. Carregado de tragicidade, o heroísmo não é moral, lembrai-nos que o mito não é histórico nem cultural, e qualquer ato do herói, circunscrito num 
espaço-tempo, que poderia ser moralmente julgado, é justificado pelo fim que visa sempre o bem da coletividade. Segundo Vargas (2006, p. 27),

O herói é um dos símbolos mais importantes existentes. Nos emocionamos com sua trajetória porque, embora sua origem seja parcialmente divina e seus feitos estejam além do humano, ele também é humano, sofre como nós, possui uma existência finita e um fim trágico. E o mais importante: o motivo da existência do herói é a realização de uma ação que beneficiará a coletividade. É seu destino.

Podemos claramente notar a forma como o mito do herói é vivenciado quando nos deparamos com o mito do artista. Ao submeter os discursos de especialistas em arte, como críticos, historiadores e mesmo artistas, à análise mitocrítica podemos claramente notar que a mitologia artística está fortemente presente na obra de arte e, principalmente, na construção da identidade artística.

Vargas nos relata que os estudos de Ernst Kris, Otto Kurz e Eckhard Neumann, "apontam um redobramento do mito do herói em mito de artista. As mesmas características heróicas são encontradas nas biografias de artistas assim como, nas análises e declarações da crítica sobre os artistas e suas obras". E continua, "O mito do artista atua como um fio invisivel que une sincronicamente observadorobra-artista, logo permite a vinculação de um determinado artista como outros de diferentes épocas" (VARGAS, Ibid, p. 27).

Podemos verificar nas biografias dos artistas, em suas próprias falas ou as da crítica, a repetição de alguns mitemas, com variações, é claro, de um relato para outro, mas mantendo certa regularidade em sua estrutura. Mesmo atualmente, apesar de artistas e críticos negando qualquer tônica mitológica, encontramos mitemas que coincidem com a trajetória do herói. Por isso pode ser interessante no estudo sobre identidade artística considerar a influência do mito e da mitologia em sua construção simbólica coletiva.

A mitocrítica é uma metodologia criada por Durand, para obras literárias que Antonio Vargas adapta para as artes plásticas, e nos relata (Ibid., p. 152), "[...] propus uma via alternativa cruzando os pressupostos epistemológicos e metodológicos apresentados 
por Durand com outros oriundos dos estudos sobre a mitologia artística." E ainda, "O resultado preserva os três pilares e assegura o lugar da obra como lugar central da discussão, mas substitui a identificação dos mitemas nas obras para localizá-los nos discursos da crítica sobre as obras e o autor e do autor sobre sua obra e seus conceitos de ser artista" (VARGAS, p 152).

Em seus estudos, Durand pôde notar que uma obra só resiste ao tempo quando se mitifica. É com o objetivo de auxiliar a identificar a mitologia nos discursos referentes às obras que surge a mitocrítica. Tal método considera a estrutura, o autor (e sua biografia) e o contexto sócio-histórico da época, que são os três pilares citados acima por Vargas. O caminho que a mitocrítica propõe é a procura da redundância nos conjuntos de mitemas.

O mitema é a menor unidade com sentido dentro da narrativa do mito, e os mitologemas são mitemas maiores, como capítulos. Por exemplo, o mitologema de origem contém mitemas como o de ascendência nobre, proteção divina, profecia, nascimento difícil e precocidade. Mas não podemos pensar em entender o mito como algo retilíneo, em partes, mas sim, em sua integralidade, é o que nos alerta Levi-Strauss (1979, p. 67-68), “[...] devemos estar conscientes de que se tentarmos ler um mito da mesma maneira que lemos uma novela ou um artigo de jornal, ou seja, linha por linha, da esquerda para a direita, não poderemos chegar a entender o mito, porque temos de apreender como uma totalidade [...]".

Pensemos ainda sobre a figura do artista. Ele não constrói sua identidade do nada, mas sim de idéias precedentes sobre o que é ser um artista. O primeiro título oficial concedido a artistas foi o de "familiar", referentes aos artistas que trabalhavam para uma determinada corte, na época o título os elevava ao status de membro da corte. Daí até antes do romantismo, os artistas conviveram relativamente bem com os que criavam a demanda por arte, os nobres e a igreja.

No romantismo, período de desencantamento com a revolução industrial e com a burguesia, começamos a notar uma abundância em relação a biografias dramáticas, narrando as infinitas faltas e necessidades passadas por determinados artistas. A influência do romantismo é contundente, visto que o modelo de artista transformador nasce nesse período, apesar de muitos pensarem 
que esse modelo tenha surgido com as vanguardas modernas. Como escreve Peter Gay (1999, p. 11), é nesse momento em que a burguesia (incluindo artistas, médicos, historiadores, etc.) começa a se deliciar e se angustiar com uma certa introspecção, visando uma busca maior do "eu", da individualidade.

Essa herança romântica é um paradoxo para o artista que busca a aproximação da arte com a vida, pois o artista romântico é o desajustado. Em Goya, por exemplo, podemos notar em sua biografia que a maior redundância se dá em torno da valorização do marginal. Também herança do romantismo é o que se refere à degradação dos corpos, ao martírio que demonstra os limites da consciência humana, está presente então, o artista criador de consciência e de verdade.

As principais características do herói é visar o bem da coletividade, como já citado, e o de transitar entre mundos, afinal, "o herói [é] a união das forças celestes e terrestres" (CHEVALIER; GHEERBRANT, 1989, p. 488). Isso se mostrará de diferentes formas na trajetória do artista. Podemos facilmente notar isso quando o mito do herói se estende para o mito da celebridade, talvez o herói mais em voga em nosso tempo. É comum relato de celebridades que depois de viverem períodos turbulentos (como a experiência com drogas) voltam para compartilhar sua experiência com a coletividade, ou em relato próprio ou de tablóides narrando como tais celebridades fazem ou pensam "qualquer coisa" própria do "mortal".

Quando o mito do herói se estende no mito do artista, podemos notar dois modelos principais: O artista guerreiro, de natureza externa tendo como principal característica anexar territórios, ou seja, ampliar o campo de atuação, e o artista asceta, de natureza interna cujo traço marcante é o de lutar com seus próprios limites, de psicopompo.

Uma parte da narrativa que para o modelo guerreiro pode ser um importante mitema, para o artista de natureza interior pode nada ser, ou ainda, ser sua ruína. Um bom exemplo é o filme que narra a vida de Jackson Pollock, artista de natureza interior. O filme nos mostra que quando surge o mitema de potência sexual é exatamente no momento de sua derrocada. Já o mesmo mitema presente na narrativa biográfica de um artista de natureza exterior se mostra como algo positivo até mesmo fator constituinte de seu 
ato criador, como por exemplo, no filme biográfico de Pablo Picasso.

Um mitema bastante freqüente é o da precocidade, dificilmente se lê alguma biografia ou texto crítico que não relate o belo desenho que o grande artista em questão fez na infância, ou como cantava aquela criança que agora se tornara um famoso tenor, mesmo sabendo que toda criança pode desenhar e cantar de forma graciosa a obter aplausos da família.

Podemos notar na crítica de Donald Kuspit (1992), que mesmo quando tentamos de alguma forma 'nos livrar' do mito do artista, acabamos por reafirmá-lo. No texto, Kaspit fala do mito do artista de vanguarda (que na verdade é bem anterior ao período dos 'ismos'), onde identifica dois modelos, o artista educador (equivalente ao guerreiro, de natureza exterior) e o artista personalista (equivalente ao asceta, de natureza interior). O primeiro, é aquele que procura revolucionar, ou seja, mudar o mundo herdado; o segundo, é aquele que entende a arte como sofrimento, sentimento que se constitui como via para um "Eu" elevado.

Cansado desses modelos pretensiosos, o autor clama pelo "artista suficientemente bom". O modelo proposto é o de um artista que se apóia na sua exclusividade, menos interessado em lutar com o mundo e mais propenso a viver em harmonia com o mundo. Este artista aceita o fato de que é parte da sociedade, pois sem a sociedade não há o "Eu". Ainda, aqui, sua sugestão parece bastante coerente, mas ao finalizar o texto onde tece sua nova proposta, mostra o quanto o mito do artista continua claramente presente ao dizer que através do novo modelo de artista suficiente bom talvez consigamos, enfim, mudar o mundo.

O mito do herói parece ser prioritariamente masculino, essa é uma questão que deixo, neste momento, em aberto. Tal fato pode ser compreensível ao entender que nossa história da arte se baseia na historiografia ocidental, eurocêntrica. Mas seria correto pensar o mito como algo que precede a história e o social e se instala no inconsciente? Se a resposta é afirmativa, como entender a falta da mulher nestas narrativas entendidas como o mito do herói? Para entender o mito do herói que se desdobra no mito do artista, teremos de, para uma futura pesquisa, analisar, se é que possível, o mito de uma heroína e achar sua estrutura nas imagens de artistas mulheres. Uma pesquisa sobre a figura da artista mulher é bastante 
interessante e relevante. Fica aqui lançado o desafio.

\section{Notas}

1 Fala do professor Dr. Antônio Vargas durante as aulas do seminário temático "mito e imagem do artista" ministrado em 2007/2 no Programa de Pós-Graduação em Artes Visuais da Universidade do Estado de Santa Catarina. Aproveito a ocasião para observar que as digressões aqui expostas são frutos de reflexões a partir das aulas deste seminário.

2 Fundado por Olga Fröbe-Kaptein e tendo como padrinho o fenomenólogo Rudolf Otto.

3 Entre elas a guerra civil espanhola, que se mostrou um conflito não só espanhol, mas europeu, quando todas as concepções políticas se materializaram nas guerrilhas.

\section{Referências}

CAMPBELL, Joseph. O heri de mil faces. São Paulo: Cultrix, 1993.

CHEVALIER, Jean; GHEERBRANT, Alain. Dicionrio de smbolos. Rio de janeiro: José Olympio, 1989.

GADAMER, Hans-Georg. A atualidade do belo: a arte como jogo, símbolo e festa. Rio de Janeiro: Brasileiro, 1985.

GAY, Peter. O corao desvelado: A experiência burguesa, da Rainha Vitória a Freud. São Paulo: Companhia das Letras, 1999.

HOBSBAWN, Eric. Era dos extremos: O breve século XX (19141991). São Paulo: Companhia das letras, 1995.

KUSPIT, Donald. El artista suficientemente bueno: más allá del artista de vanguardia. Revista Creacin n.. 5, Maio, Instituto de Estética de Madrid: Madrid, 1992.

LEVI-STRAUSS, Claude. Mito e significado. Lisboa: Edições 70, 1979.

MANGUEL, Alberto. Lendo imagens: uma história de amor e ódio. São Paulo: Companhia das Letras, 2003.

VARGAS, Antonio. A arte do mito: considerações sobre a influência da mitologia artística.. Florianópolis: Apostila não publicada, 2006.

VARGAS, Antonio. Do valor da prática a prática de valor. In: Ponto de vista revista de educao e processos inclusivos. v. 6/7. Florianópolis: UFSC, 2005. 


\section{Filmes}

POLLOCK. Direção: Ed Harris. Produção: Brant-Allen, Fred Berner Films, Pollock Films, Zeke Productions. Roteiro: Steven Naifeh, Gregory White Smith, Barbara Turner, Susan J. Emshwiller. Intérpretes: Ed Harris, Marcia Gay Harden, Tom Bower, Jennifer Connellye outros. [E.U.A: California filmes], 2000. 1 fita de vídeo (122 min).

OS AMORES DE PICASSO. Direção: James Ivory. Produção: Ismail Merchant e David L. Wolper. Roteiro: Ruth Prawer Jhabvala, baseado em livro de Arianna Stassinopoulos Hoffington. Intérpretes: Anthony Hopkins, Natascha McElhone, Julianne Moore, Joss Ackland e outros. [E.U.A: Warner Bros], 1996. 1 fita de vídeo (125 $\min )$.

\section{Apoio}

GARAGALZA, Luis. Filosofía e historia en la Escuela de Eranos. In: Anthopos Revista de documentacin cientfica de la cultura. Barcelona: Anthropos, n.153, 1994.

ORTIZ-OSÉS, Andrés. El círculo eranos: origem y sentido. In: Anthopos Revista de documentacin cientfica de la cultura. Barcelona: Anthropos, n. 153, 1994.

VARGAS, Antonio. A influência do mito do herói na aceitação das práticas artísticas. In: CONCINNITAS: Revista do Instituto de Artes da UERJ. Rio de Janeiro: UFRJ, Ano 7, v. 1, n.9, 2006.

VARGAS, Antonio. Antropologia simbólica: hermenêutica do mito do artista nas artes plásticas. In BULHÕES, M. A.; KERN, M. L. (org). As questes do sagrado na arte contempornea da Amrica Latina. Porto alegre: UFRGS, 1997.

VARGAS, Antonio. Apontamentos para o estudo da identidade artística. In: Urdimento Revista de estudos ps-graduados em artes cnicas. Florianópolis: UDESC/CEART, v. 1, n.07, 2005. 
VISUALIDADES. REVISTA DO PROGRAMA DEMESTRADO EM CULTURA VISUAL - FAVIUFG 
O mito do artista como extensão do mito do herói

Francielly Rocha Dossin

Mestre em Artes Visuais pelo Programa de Pós-Graduação em Artes Visuais - PPGAV, Centro de Artes da Universidade do Estado de Santa Catari- 